\title{
Optimal Investment Strategy under Stochastic Interest Rates
}

\author{
Adeline Peter Mtunyaa ${ }^{1,2^{*}}$, Philip Ngare ${ }^{3}$, Yaw Nkansah-Gyekye ${ }^{1}$ \\ ${ }^{1}$ School of Computational and Communication Science and Engineering, Nelson Mandela African Institution of Science and \\ Technology, Arusha, Tanzania \\ ${ }^{2}$ Faculty of Science, Mkwawa University College of Education, Iringa, Tanzania \\ ${ }^{3}$ School of Mathematics, University of Nairobi, Nairobi, Kenya \\ Email: *mtunyaa@nm-aist.ac.tz, pngare@uonbi.ac.ke, yaw.nkansah-gyekye@nm-aist.ac.tz
}

How to cite this paper: Mtunya, A.P., Ngare, P. and Nkansah-Gyekye, Y. (2017) Optimal Investment Strategy under Stochastic Interest Rates. Journal of Mathematical Finance, 7, 319-332. https://doi.org/10.4236/jmf.2017.72017

Received: February 17, 2017

Accepted: May 15, 2017

Published: May 19, 2017

Copyright $\odot 2017$ by authors and Scientific Research Publishing Inc. This work is licensed under the Creative Commons Attribution International License (CC BY 4.0).

http://creativecommons.org/licenses/by/4.0/ (c) (i) Open Access

\begin{abstract}
We study how firms' management can make effective investment decision under the influence of random interest rates. We define the threshold interest rate value below which investment can be effectively done and above which investment is not optimal. We use a stochastic differential equation with alternating drift to find the optimal investment policy under stochastic interest rate. One of our results indicated that, the optimal condition for investment expansion is when the interest rate is low and the profit level is high. Also, there exists the threshold interest rate value which forms the basis for investment decision of a company. Moreover, we revealed that it is not optimal for the managers to plan for firm's business expansion when is already making extremely high profits. At the end we were able to confirm that business is generally more stable when the interest rates are lower than those when they are high. Since firms in emerging economies suffer most from interest rate fluctuations, they need more effective investment strategies. Monetary policy makers of such economies need to ensure low interest rates in order to promote firms' investment and therefore boost the general economy.
\end{abstract}

\section{Keywords}

Firm Investment Strategy, Interest Rates, Emerging Market Countries, Stochastic Optimal Control

\section{Introduction}

The variation of the interest rates affects business decision about how to save and invest [1] [2]. Fundamentally, a rise in interest rates has a sizable negative effect on capital expenditures by businesses. In economic theory, the cost of cap- 
ital has an important influence on decisions to invest and, therefore, affects business cycles in general [3]. The market interest rate is considered to be a key building block in the firm's user cost of capital, which, combined with the resulting stream of expected cash flows, constitute the primary determinants of whether and how much to invest [4] [5] [6]. Calderón and Fuentes [7] point out that an increase in the country's interest rates raises their effective labour costs. Labour cost is usually one of the basic considerations for business expansion. It is also argued by Chetty [8] that finding out how does an increase in interest rates affect capital investment by firms has important implications for monetary and fiscal policies. Studies have revealed that the impacts of interest rates on capital investment are more substantial in emerging market countries (EMCs) as compared to developed economies [2] [7] [9] [10]. This sets the benchmark as to why business planning in the EMCs needs to consider the fluctuations of the interest rates.

This study focuses on the problem of a company that wants to optimize the use of its revenue in the expansion of its investment which is highly sensitive to the fluctuations in the interest rate. We show how the firm's financial managers can ensure maximum growth in the investment while avoiding high capital expenditures caused by increase in interest rates. The maximum growth in investment is calculated as the present value of all the future investment expenditures. Most models on firm's investment found in the literature do not account for the effect of interest rate fluctuations as one of the key determinants of the investment strategy. Our main contribution, therefore, is to consider the effect of interest rate in the investment side of the model proposed by Décamps and Villeneuve [11], albeit in a modified and simplified presentation.

The effect of uncertainty on firm investment attracts a lot of attention in the literature [12] [13] [14]. Bader and Malawi [15] investigated the impact of real interest rate on investment level in Jordan and found that real interest rate has a negative impact on investment. Bo and Sterken [12] analyzed the joint impact of the interest rate volatility and debt on firm investment of Dutch listed firms. One of their findings showed that the effect of the level of the interest rate on investment is significant and negative, and the level effect of the interest rate on investment turns to be larger for less-indebted firms than for highly indebted firms. Since it is logical that a less-indebted firm or especially a non-indebted firm is the one in a better position to use generated profit for growth in investment, then consideration of interest rate in investment is very important. Their study provided the cross-effect of the interest rate volatility and debt on investment. However, there misses an actual strategy which should be adopted by firms when high interest rates have a significant impact on investment. Our study fills this gap by providing a strategy that accounts for interest rates on firms' investments explicitly.

Most studies consider investment growth decision of a firm in connection with dividend payments and/or consumption rates [11] [13] [16] [17]. Décamps and Villeneuve [11], for example, study the interactions between dividend policy 
and investment decision in a growth opportunity and under uncertainty. In particular, they consider a firm with a technology in place that has the opportunity to invest in a new technology that increases its profitability. The firm self-finances the opportunity cost on its cash reserve rather than concentrating on the collected revenue as in our case. However, they do not present explicitly the optimal level of investment and the actual potential investment stopping times. On the other hand the study by Chevalier, Vath and Scotti [13] considered the problem of determining the optimal control on the dividend and investment policy of a firm. In addition, they considered the fact that the firm carries a debt obligation in its balance sheet. They came up with a combined singular and multiple-regime switching control problem whereby each regime corresponds to a level of debt obligation held by the firm. While they considered debt as a means to further investment, in our case we consider the collected revenue of a firm as main source of funding the investment growth. Hugonnier, Malamud and Morellec [18] developed a model of investment, financing, and cash management decisions in which investment is lumpy and firms face capital supply uncertainty. They assumed that firms have to search for investors when in need of capital for investment and therefore it faces uncertainty regarding its ability to raise funds in capital markets. They showed that firms with high investment costs differ in their behaviors from firms with low investment costs and firms may rise outside funds before exhausting internal resources. Their analysis also revealed that investment and payout do not always increase with slack and that the choice between internal and external funds does not follow a strict pecking order. In our study we focus on internal funds, profit in particular, in which decision can be made whether to invest or consume. As we appreciate the impacts of interest rates on making investment decision, we build on such studies by providing a means to make more effective investment decisions. This is a requirement for growing firms particularly in emerging markets.

Several facts collectively stand as the basis of our motivation to undertake this study. First we are motivated by the fact that there is a great discrepancy on the effect of interest rate between the developed and the emerging economies as explained in [2] [7] [9] [10]. Since firms operating in the emerging economies suffer most from the fluctuations in the interest rates, their contribution to the economy will also be limited and therefore there is a necessity to make them plan more effectively under the same circumstance. Secondly, in such emerging economies business is more affected by macroeconomic shocks, therefore providing a means for firms to plan against interest rates will pave the way to combat other factors such as transaction costs and exchange rates. Also the role of firms' investments in transforming the economies of emerging market countries (EMCs) is enormously significant thus needs special attention. Moreover, it is argued that due to the availability of natural resources, labour and consumer markets in such countries, there are always opportunities for the firms to grow. This is why having effective strategies for the growth of firms in such contexts remains a necessity. 
In our study we model investment as related to revenue rather than simply the cash holding of a firm because we assume that from the collected revenue the decision is immediately made on whether to expand investment or consume (or pay dividend). Such a managerial decision is made depending on the level of the interest rate which is assumed to be a continuous stochastic process that can generally be modeled as a term structure. Gibson, Lhabitant and Talay [19], and Huang, Sun and Chen [20] provide appealing presentations of the term structure models of interest rates. Akyildirim et al. [21] provide a means of applying stochastic interest rates in the optimization of dividend payouts. Apart from the fact that their stochastic optimal control was on dividends and ours is on investment, their interest rate had only two states one for good economic state and the other for bad economic state. In our case we consider the interest rate that varies continuously and apply a stochastic discount factor in the optimization of investment level. This is because naturally the economy cannot have only two states but varies randomly in its spectrum.

The outline of this paper is as follows. Section 2 gives model formulation, explanation on threshold interest rate value and investment cost, and definition of the objective function. In section 3, we state the properties of the value function and provide proofs. We show that the value function for our objective function exists and it is unique and concave in both the profit and interest rate variables, thus can be a solution of the dynamic programming equation. In section 4 , we carry-out numerical experiment. We provide a plot that gives the general overview of the value function over the interest rates and the profit levels. We present a numerical determination of the threshold interest rate value. We also give a numerical test for the sensitivity of the value function on the drift for different interest rates and profit levels. In section 5, we summarize the results of our study and make a conclusion.

\section{Model Formulation}

Uncertainty is described by a probability space $(\Omega, \mathcal{F}, \mathbb{P})$ and a filtration $\left(\mathcal{F}_{t}\right)_{t \geq 0}$ satisfying the common assumptions. Let $B_{t}$ be one dimensional $\left(\mathcal{F}_{t}\right)$ - standard Brownian motion. We consider a firm whose business generates profit $Y_{t}$ that follows a Stochastic Deferential Equation (SDE) with a drift $\alpha_{0}$ and volatility $\beta$ presented as

$$
\mathrm{d} Y_{t}=\alpha_{0} \mathrm{~d} t+\beta \mathrm{d} B_{t} .
$$

The firm operates in a floppy macroeconomic environment whereby the interest rate $r$ varies randomly between the lowest possible interest rate and the highest possible interest rate. The dynamics of interest rates is assumed to be a continuous stochastic process representing the state of economy. Depending on the state of economy, the firm may opt to channel a portion $G$ of the profit $Y$ to further its investment which will increase the drift from $\alpha_{0}$ to $\alpha_{G} \geq \alpha_{0}$. We assume that there is no alteration in the volatility $\beta$. The drift $\alpha_{G}$ is proportional to the investment cost $G$. The firm has to define the threshold interest rate 
$r_{\theta}$ from which the firm can further its investment only when $r \leq r_{\theta}$ otherwise channels its profit into other uses such as dividend payments. The investment cost $G_{t}$ at time $t$ which must be financed from the profit made $Y_{t}$ is positive non-decreasing right continuous and adapted to the interest rate process $r_{t}$. The set $\left\{t: r_{t} \leq r_{\theta}\right\}$ consists of all possible stopping times $\tau$ at which investment can be done. We therefore model the profit trend subject to investment as follows;

$$
\mathrm{d} Y_{t}=\left(\alpha_{0} \mathbb{1}_{t<\tau}+\alpha_{G} \mathbb{1}_{t \geq \tau}\right) \mathrm{d} t+\beta \mathrm{d} B_{t}-\mathrm{d} G_{t}, Y_{0}=y .
$$

This is a simplified version derived from the cash reserve model given by [11] from which we concentrate in the side of investment and consider stochastic interest rate in the optimization later.

We consider the fact that at any time $t$ and the interest rate $r_{t}, 0 \leq G_{t} \leq Y_{t}$ and also the more the profit the higher is the upper limit level of optimal investment. This is represented by the following relationship

$$
G_{t} \leq\left(1-\mathrm{e}^{-\left(r_{\theta}-r_{t}\right)}\right) Y_{t} .
$$

The increment in the drift at time $\tau$, from $\alpha_{0}$ to $\alpha_{G}$ depends on the ratio of the investment made $G_{\tau}$ to the profit $Y_{\tau}$. In fact, the relationship between $\alpha_{G}$ and $\alpha_{0}$ is given by

$$
\alpha_{G}=\alpha_{0}+\frac{G_{\tau}}{Y_{\tau}} \leq \alpha_{0}+\frac{\left(1-\mathrm{e}^{-\left(r_{\theta}-r_{\tau}\right)}\right) Y_{\tau}}{Y_{\tau}}=\alpha_{0}+\left(1-\mathrm{e}^{-\left(r_{\theta}-r_{\tau}\right)}\right) .
$$

We make an assumption that the company should make positive profit for its survival, otherwise it has to undergo bankruptcy. We therefore define the bankruptcy time by

$$
\mathrm{T}=\inf \left\{t \geq 0: Y_{t}<0\right\} .
$$

Our aim is to study the optimal investment strategy of a firm as related to the variations in the interest rates. The firm wants to invest as more as it is feasible but is challenged by the fluctuation of the interest rates. Given as initial conditions the value of the profit $\mathrm{y}$ and the corresponding interest rate $r$, we denote the set of all admissible investment costs and the stopping times $(G, \tau)$ by $\mathcal{A}(y)$. The investment costs and the stopping times constitute the control policy $\left(G_{t}, \tau, t \geq 0\right)$. Mathematically, the optimal investment problem is to maximize the value function

$$
H(y, r ; G, \tau)=\mathbb{E}^{y, r}\left[\int_{0}^{\top} \Lambda_{t} \mathrm{~d} G_{t}\right] \text {, where } \Lambda_{t}=\exp \left(-\int_{0}^{t} r_{s} \mathrm{~d} s\right) .
$$

The corresponding optimal value function is then defined as

$$
v(y, r)=\sup _{(G, \tau) \in \mathcal{A}(y)} H(y, r ; G, \tau)
$$

and the optimal policy $\left(G_{t}^{*}, \tau^{*}\right)$ is such that

$$
H\left(y, r ; G_{t}^{*}, \tau^{*}\right)=v(y, r) .
$$




\section{The Value Function}

We present analytically the characterization of the optimal value function. Our main goal is to maximize the expected investment fund discounted under a stochastic interest rate and finding the optimal stopping times for investments to be done. In fact the stopping times are evaluated from the threshold interest rate $r_{\theta}$ as elaborated in the previous section.

We state the following theorem which summarizes the key features of the optimal value function. Important to mention these features are the uniqueness and concavity properties. Prior to stating the theorem we define the differential operator for $v$, by considering the stochastic interest rate $r$, as

$$
\mathcal{L} v(y, r):=\left(\alpha_{0} \mathbb{1}_{t<\tau}+\alpha_{G} \mathbb{1}_{t \geq \tau}\right) \frac{\partial}{\partial y} v(y, r)+\frac{1}{2} \beta^{2} \frac{\partial^{2}}{\partial y^{2}} v(y, r)-\frac{\partial}{\partial r} v(y, r)
$$

and use it in the theorem statement.

Theorem 1. The optimal value function $v=v(y, r)$ is the unique concave function satisfying the following conditions: [label=.]

1. $v \in C^{2}([0, \infty))$ and $v(0, r)=0$,

2. $\frac{\partial}{\partial y} v(y, r) \geq 1$ for all $y, r$,

3. For every $y>0, r>0$,

$$
\mathcal{L} v(y, r)-r v(y, r) \geq 0 .
$$

The formation of this theorem is analogous to the one given by [21] when dealing with optimal dividend policy. However, the statements in this theorem consider a continuous stochastic interest rate as it also appears in the third term of the differential operator. This leads to a different approach in the analysis since the value function depends on two continuous independent variables $y$ and $r$.

We take into account the argument that it is preferable to allocate fund from profit to further investment when the interest rate is below the threshold interest rate value $r_{\theta}$ over when the interest rate is above this threshold value.

From the theorem stated above we find that the optimal value function is represented as the solution of the following dynamic programming equation

$$
\max \left\{\mathcal{L} v(y, r)-r v(y, r),-v_{y}(y, r)+1\right\}=0, \quad y>0, r>0
$$

having the boundary condition $v(0, r)=0$ and initial condition $v(y, 0)=0$. We have used the subscript to represent a partial derivative with respect to a variable. Also from this point onwards, we shall be using $\hat{\alpha}$ in the place of the expression $\left(\alpha_{0} \mathbb{1}_{t<\tau}+\alpha_{G} \mathbb{1}_{t \geq \tau}\right)$ which simplifies the analysis without destroying the intended meaning. Actually, the fact that $\hat{\alpha}$ takes the value of either $\alpha_{0}$ or $\alpha_{G}$ at a time is dealt with numerically by the sensitivity of the value function $V$ to $\hat{\alpha}$ in Section 4 .

The representation in Equation (11) is actually a Hamilton-Jacobi-Bellman (HJB) equation characterized by the following system of equations 


$$
\begin{aligned}
& \mathcal{L} v(y, r)-r v(y, r)=0, \text { for } y>0, r>0, \\
& v_{y}(y, r)=1 \text {, for } y>0, r=r_{\theta}, \\
& v(0, r)=0 .
\end{aligned}
$$

It can be seen clearly that Equation (12) is a second order linear partial differential equation (PDE) of parabolic type with initial and boundary conditions given by Equations (13) and (14) respectively.

Next, we prove Theorem 1 above by considering the PDE with the initialboundary conditions above. To the best of our experience, we have never come across an attempt to prove the existence and uniqueness of the value function by means of reducing the dynamic programming equation into a simple diffusion equation as it is done here.

Proof. Since a simple diffusion equation has a solution, we attempt the proof for existence of solution for $v$ as given in Equation (12) by transformation of the equation into a simple diffusion equation. This is done by the change in variables. We write Equation (12) in an expanded form with subscript notation as

$$
-v_{r}+\frac{1}{2} \beta^{2} v_{y y}+\hat{\alpha} v_{y}-r v=0, \quad y>0, r>0 .
$$

Changing $v$ to $u$ by $u=v \mathrm{e}^{\frac{1}{2} r^{2}}$ implies

$$
v=\mathrm{e}^{-\frac{1}{2} r^{2}} u, v_{r}=-r \mathrm{e}^{-\frac{1}{2} r^{2}} u+\mathrm{e}^{-\frac{1}{2} r^{2}} u_{r}, \quad v_{y}=\mathrm{e}^{-\frac{1}{2} r^{2}} u_{y}, \quad v_{y y}=\mathrm{e}^{-\frac{1}{2} r^{2}} u_{y y} .
$$

Which after substitution simplify Equation (15) to

$$
-u_{r}+\frac{1}{2} \beta^{2} u_{y y}+\hat{\alpha} u_{y}=0, \quad y>0, r>0 .
$$

Next we transform the independent variables $y, r$ to $\eta=y-\hat{\alpha} r, \rho=r$ which leads to a simple diffusion equation under $w$,

$$
-w_{\rho}+\frac{1}{2} \beta^{2} w_{\eta \eta}=0, \eta>0, \rho>0 .
$$

This can be written as

$$
w_{r}-\frac{1}{2} \beta^{2} w_{y y}=0, \quad y>0, r>0,
$$

with a complete transformation given by

$$
v(y, r)=w(y, r) \mathrm{e}^{\frac{\hat{\alpha}}{\beta^{2}}(y-\hat{\alpha} r)-\frac{r^{2}}{2}} .
$$

Therefore, the solution for (15) and thus for (12) exists.

Uniqueness can now be shown from Equation (18).

Lemma 1. The diffusion equation presented by (18) with some given initial and boundary conditions deduced from (13) and (14) has a unique solution.

Proof. Suppose that $w_{1}$ and $w_{2}$ are solutions to the Equation (18), we show that $x=w_{1}-w_{2}=0$. The function $x$ also satisfies (18) and the boundary conditions. We define the function $\psi$ by 


$$
\psi(r):=\int_{0}^{\infty}[x(y, r)]^{2} \mathrm{~d} y .
$$

Differentiation under the integral sign leads to

$$
\begin{aligned}
\frac{\mathrm{d}}{\mathrm{d} r} \psi(r) & =2 \int_{0}^{\infty} x(y, r) x_{r}(y, r) \mathrm{d} y \\
& =2 \int_{0}^{\infty} x(y, r)\left(\frac{\sigma^{2}}{2}\right) x_{y y}(y, r) \mathrm{d} y .
\end{aligned}
$$

Integrating by parts in the variable $y$ we find

$$
\frac{\mathrm{d}}{\mathrm{d} r} \psi(r)=\left.\beta^{2} x(y, r) \cdot x_{y}(y, r)\right|_{0} ^{\infty}-2 \int_{0}^{\infty}\left[x_{y}(y, r)\right]^{2} \mathrm{~d} y .
$$

From the boundary and initial conditions we deduce that

$$
x_{y}(0, r)=x_{y}(\infty, r)=x(y, 0)=0 .
$$

Thus

$$
\frac{\mathrm{d}}{\mathrm{d} r} \psi(r)=-2 \int_{0}^{\infty}\left[x_{y}(y, r)\right]^{2} \mathrm{~d} y \leq 0 .
$$

So, $\psi(r)$ is decreasing in $r$. We find that since $\psi(0)=0$ and since $\psi(r) \geq 0$ then $\psi(r)=0$ for all $r>0$. Hence $x=0$.

Now, we prove the concavity of $v$. Different from what is common in most of the literature [21] [22], where the concavity of the value function is proved only w.r.t the variable $y$, we prove the concavity of $v$ in both $y$ and $r$. This is because $v$ in our case varies in both variables $y$ and $r$. We fix $r$ and show that $v$ is concave in $y$ and conversely.

Lemma 2. The solution of the PDE given in (15) is concave on both of the independent variables $y$ and $r$.

Proof. We first arbitrarily fix $r$ at $\bar{r}$ and thus Equation (15) becomes

$$
\frac{1}{2} \beta^{2} v_{y y}+\hat{\alpha} v_{y}-\bar{r} v=0
$$

This is an ODE w.r.t the variable $y$ with the general solution

$$
v(y, \bar{r})=c_{1} \mathrm{e}^{k_{1} y}+c_{2} \mathrm{e}^{k_{2} y},
$$

where $c_{1}, c_{2}$ are real constants and $k_{1}, k_{2}$ are also real numbers given by

$$
\begin{aligned}
& k_{1}=\frac{1}{\beta^{2}}\left(-\hat{\alpha}+\sqrt{\hat{\alpha}^{2}+2 \beta^{2} \bar{r}}\right), \\
& k_{2}=\frac{1}{\beta^{2}}\left(-\hat{\alpha}-\sqrt{\hat{\alpha}^{2}+2 \beta^{2} \bar{r}}\right) .
\end{aligned}
$$

It is observed that $k_{2}<0<k_{1}$ and from the boundary condition (14) we have $c_{1}+c_{2}=0$. We consider a fixed point $\bar{y}$ satisfying the condition given by (13) and find every function satisfying the Equations (12) to (14) has the form

$$
v(y, \bar{r})= \begin{cases}c_{1}\left(\mathrm{e}^{k_{1} y}-\mathrm{e}^{k_{2} y}\right), & 0<y<\bar{y}, \\ y-\bar{y}+v(\bar{y}, \bar{r}), & y \geq \bar{y}\end{cases}
$$

Assuming that $v$ is $C^{2}$ at $\bar{y}$, we use the smooth-pasting condition for sin- 
gular control to determine $c_{1}$ and $\bar{y}$. The condition leads to

$$
\begin{aligned}
& c_{1} k_{1} \mathrm{e}^{k_{1} \bar{y}}+c_{2} k_{2} \mathrm{e}^{k_{2} \bar{y}}=1, \\
& c_{1} k_{1}^{2} \mathrm{e}^{k_{1} \bar{y}}+c_{2} k_{2}^{2} \mathrm{e}^{k_{2} \bar{y}}=0,
\end{aligned}
$$

from which we obtain

$$
\bar{y}=-\frac{\ln \left(k_{1}^{2}\right)-\ln \left(k_{2}^{2}\right)}{k_{1}-k_{2}},
$$

and from $k_{2}<0<k_{1}$,

$$
C_{1}=\left[k_{1}\left|\frac{k_{2}}{k_{1}}\right|^{\frac{2 k_{1}}{k_{1}-k_{2}}}-k_{2}\left|\frac{k_{2}}{k_{1}}\right|^{\frac{2 k_{2}}{k_{1}-k_{2}}}\right]^{-1}>0 .
$$

From (25) and (26) with (30) it can be established that $\bar{y}>0$ is necessary and sufficient for $\hat{\alpha}>0$. We find that the function $\mathrm{v}$ as presented by (27) is well defined if and only if $\hat{\alpha}>0$ and since $\bar{y}>0$ we get that $v$ is concave w.r.t the variable $y$.

Next we also arbitrarily fix $y$ at $y^{*}$ and therefore Equation (15) becomes

$$
-v_{r}-r v=0 \text {. }
$$

We simply solve for $v$ and have

$$
v\left(y^{*}, r\right)=\mathrm{e}^{-\frac{r^{2}}{2}}
$$

which is concave up.

As the consequence of the proof of the theorem given above we have the following corollary about the value function.

Corollary 1. Consider the maximization problem of the value function $H(y, r ; G, \tau)$ over all strategies $(G, \tau)$ in the admissible set $\mathcal{A}(y)$. Then the concave solution $v$ to the HJB Equation (11) with the drift $\hat{\alpha}>0$ given by (27) under fixed $r$ where the constants $\bar{y}$ and $c_{1}$ are as found in (30) and (31), and that appears as (33) under fixed $y$, is the optimal value function.

\section{Numerical Results and Discussion}

Under this section, we illustrate how the value function varies in relation to the interest rates and the profit levels. We mainly consider the PDE as it appears in (12) and (15). We begin by providing a three dimensional plot that gives a general outlook of the dependence of the value function on the interest rates and the profit levels. The next two figures show how the value function varies over the interest rates at different profit levels and how it varies over the profit values at different interest rates. The former will be helpful in estimating the threshold interest rate $r_{\theta}$ which is in fact the point where the value function is the same for high and low profit levels. The last two illustrations are about sensitivity of the value function to the generalized profitability $\alpha$ for different values of interest rate and profit levels. The parameter values for profitability and volatility have been adopted from the study by [23] and the interest rates are the results of 
estimation.

In Figure 1 we generally observe that the value function increases as the interest rate decreases and also it increases as the profit level increases. This automatically suggests that the favourable time to invest is when the interest rate is low and the profit level is high, a fact which is detailed in Figure 2.

In Figure 2, we find that the value function drops exponentially as the interest rate increases when the profit level is high whereas a moderate increase is

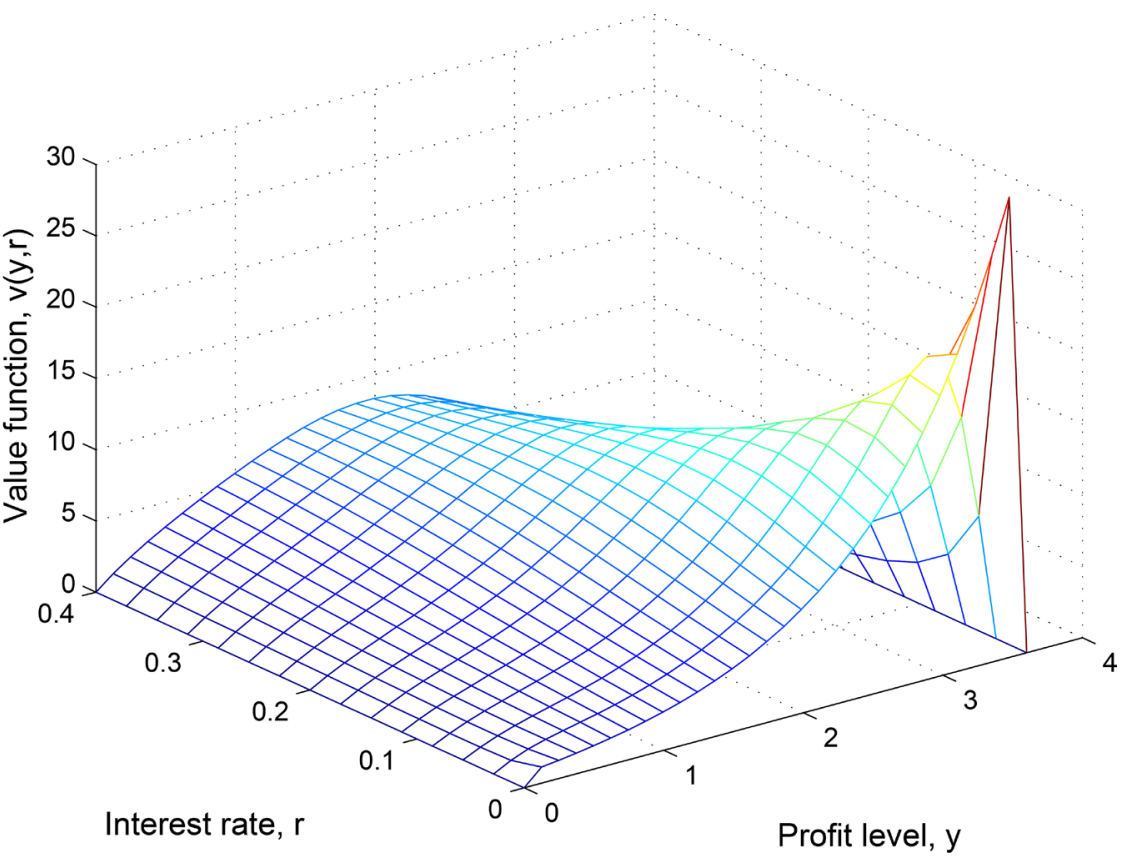

Figure 1. General overview of the value function over the interest rate and profit level with $\alpha=1.5$ and $\beta=1.5$.

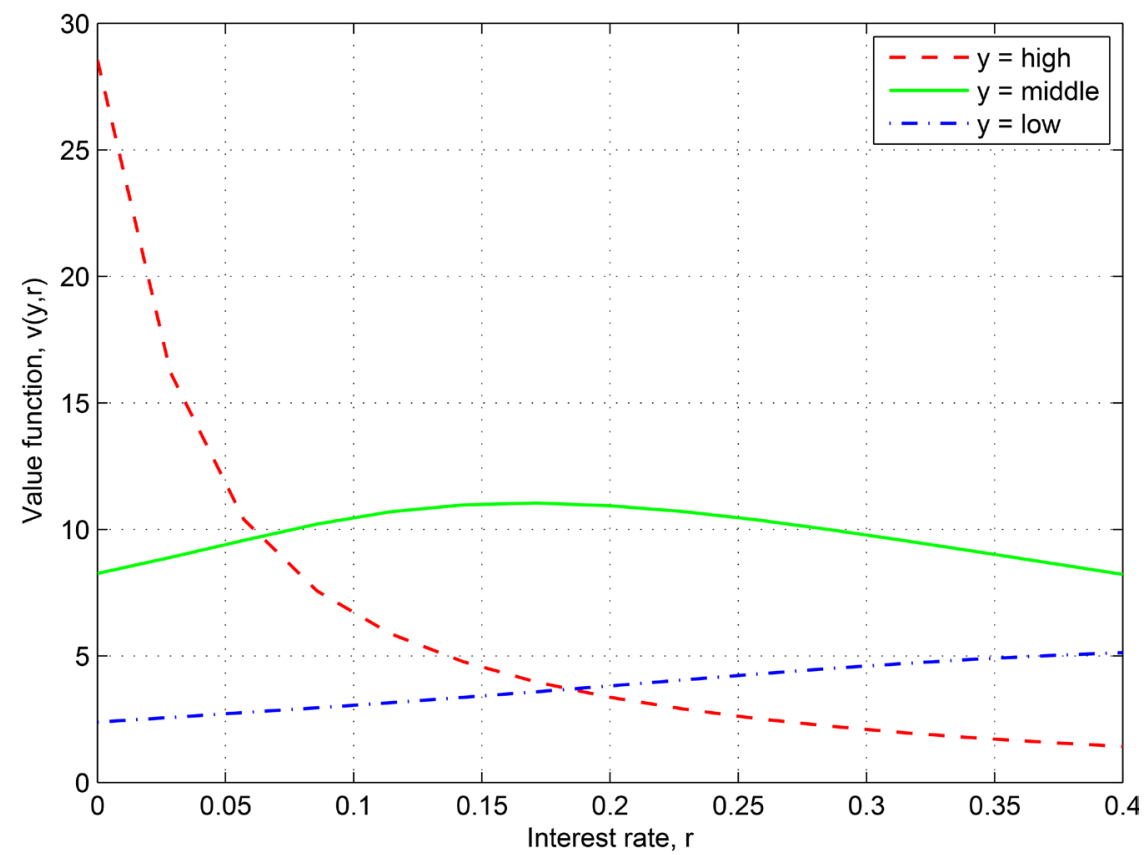

Figure 2. Variation of the value function over interest rate $r$ for different levels of profit $y$. 
experienced as to the increase in interest rate when the profit level is low. At the middle level of profit there is a moderate increase followed by a moderate drop. The curve for high profit and the curve for low profit cross each other at the point with $r \approx 0.18$, this gives the threshold interest rate $r_{\theta}=18 \%$. Since it is a contradiction to further investment under low profit, we consider the high profits which give higher value function when the interest rate $r<r_{\theta}$.

By inspection, Figure 3 establishes the fact that the value function has significantly high values when the interest rate is low and the profit level is high. However, at extreme high profit values the value function starts to drop which means theoretically that it is not appropriate to consider business growth when profit is at extreme.

Both Figure 4 and Figure 5 portray that the value function $v$ is more sensitive to the parameter $\alpha$ when the interest rates are high and less sensitive when the interest rates are low, regardless of the profit levels. This indicates that business is more stable when the interest rates are low than when the interest rates are high. In addition, we learn from Figure 4 that at some points having high profitability combined with high levels of profit is not suitable to expand investment as compared to relatively low profitability.

\section{Conclusion, Recommendation and Possible Extensions}

In this work, we have set up a strategy for a company that wants to maximize its investment under the context of randomly fluctuating interest rates. We considered a company that operates in a floppy economy, such as that of developing countries, and generates profit which can be modeled by a SDE. The company has to identify the threshold interest rate value, above which investment is not a feasible decision.

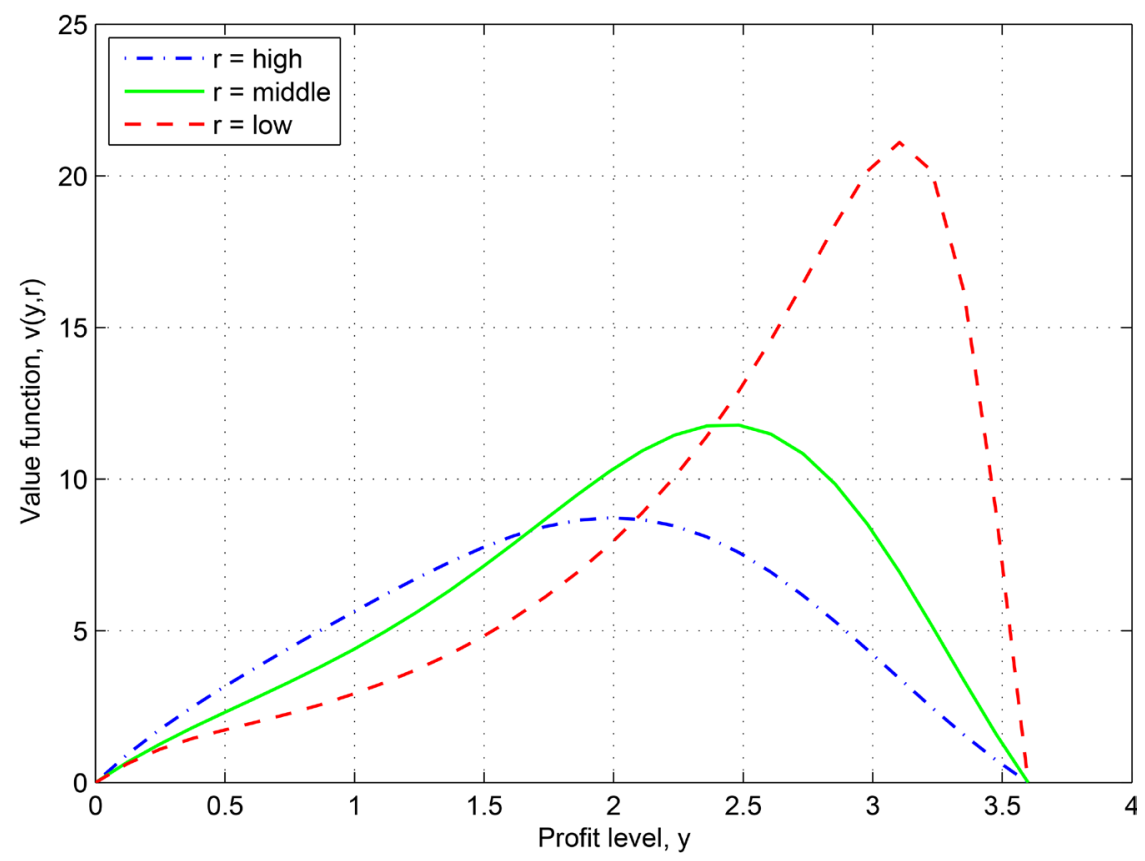

Figure 3. Variation of the value function over profit level $y$ for different interest rates $r$. 


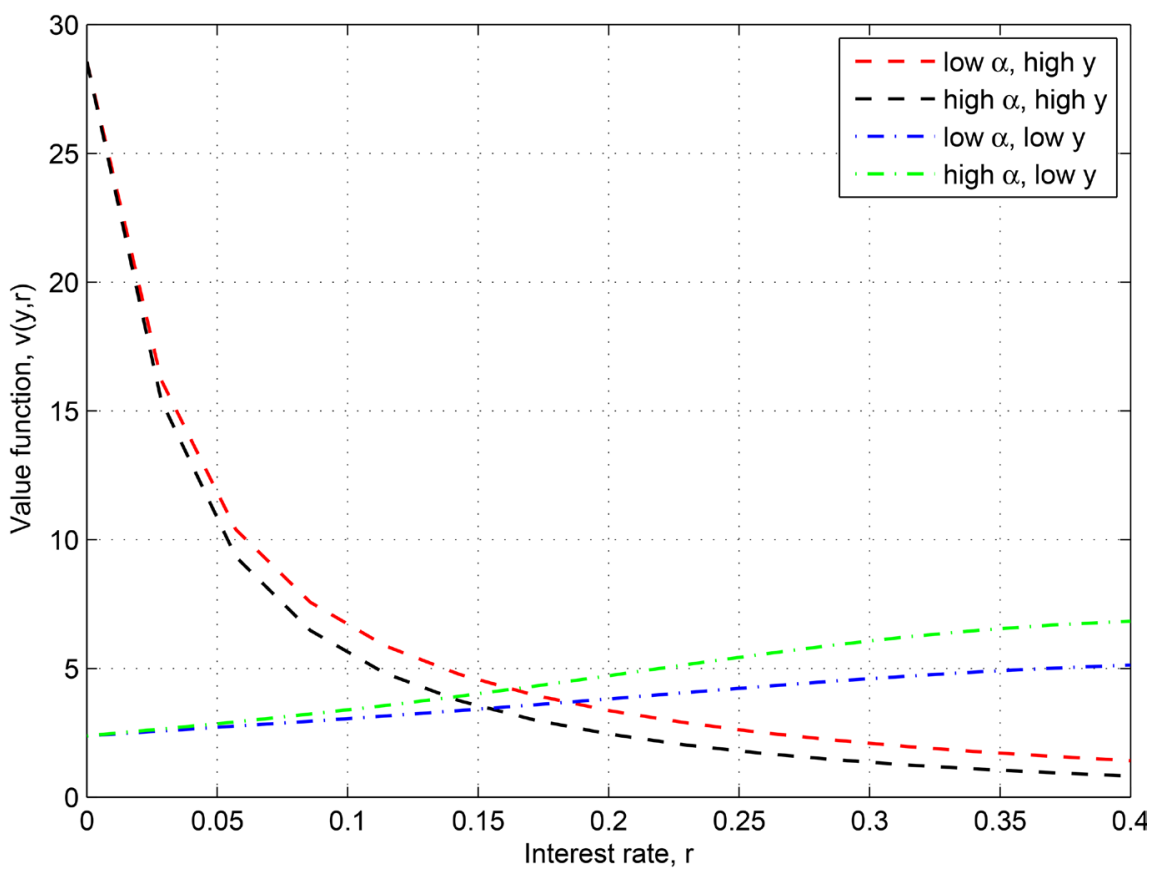

Figure 4. Sensitivity of the value function w.r.t profitability $\alpha$ under the interest rates $r$.

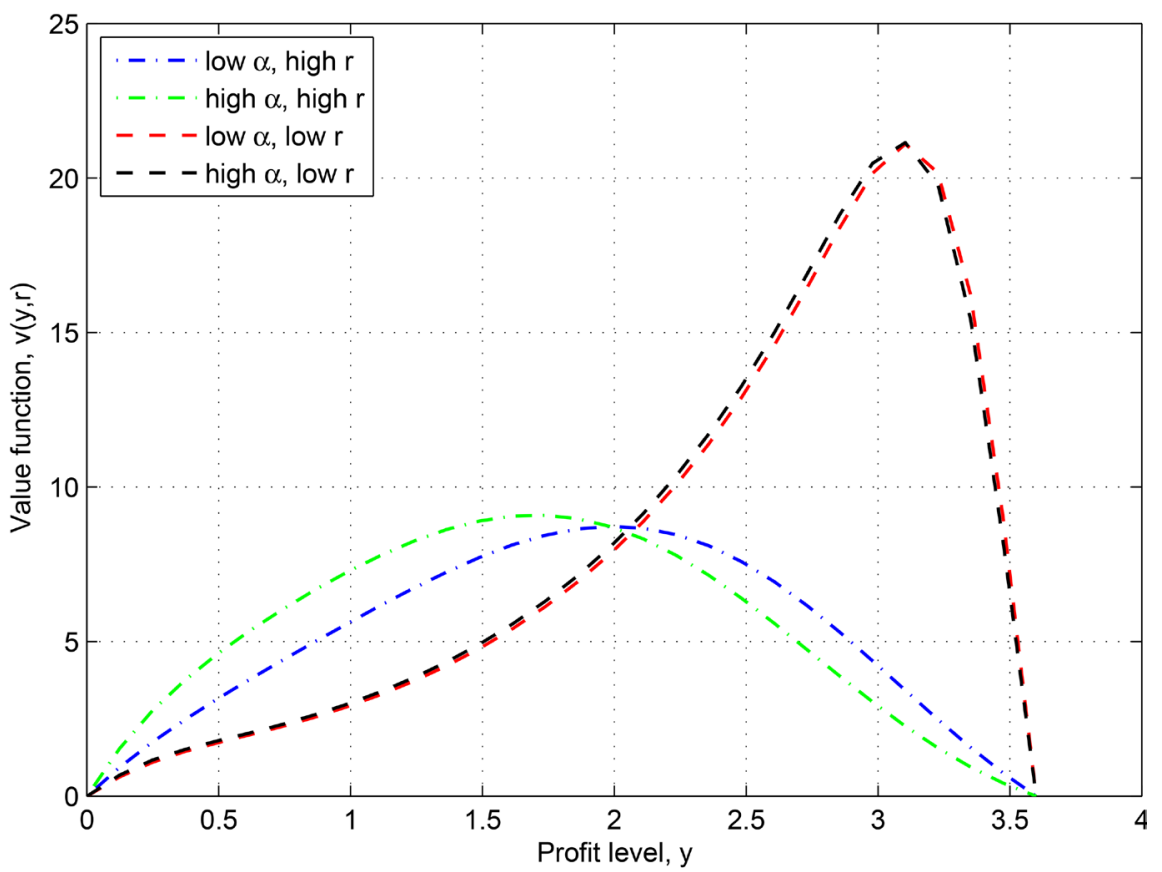

Figure 5. Sensitivity of the value function w.r.t profitability $\alpha$ under the profit levels $y$.

From this study, we find mainly four results which we explain in summary. First we find that the value function increases as the interest rate decreases and it also increases as the profit level increases. This is to say that the interest rate and the profit level have opposing influence in the maximization policy on investment. The second and vital result of this study is the existence of a threshold value for the interest rate $r_{\theta}$ for a given firm which can stand as the basis for making interest rate based investment decision. For the parameters we have, 
such a threshold interest rate is about $18 \%$. Monetary policy makers may make sure that the interest rates are well standardized to be below this value in order to promote investment by firms in emerging market countries. Thirdly we find that it is not advisable for companies to plan for expansion of their business when are already making extremely high profits from the business they are undertaking. Possibly a good advice for such companies is to plan for investing on other kinds of business as they enjoy higher profits from the existing business. Lastly we revealed that business is more stable when the interest rates are low than when the interest rates are high. Though this can be obvious in economic terms, we explicitly presented here in relation to the investment decision of firms, so that the decision making on investment considers the role of interest rate to be of major concern.

As a consequence of this study, a combined optimal dividend and investment policy under stochastic interest rate can be studied. In such a study, the attention can be in the maximization of dividend payments and accumulating some fund for investment or conversely. As an extension to this study, it can also be possible to find the optimal time for accessing loan for investment under stochastic interest rates.

\section{Acknowledgements}

The study by Adeline P. Mtunya is under the sponsorship of the Government of The United Republic of Tanzania through the Commission for Science and Technology (COSTECH). The authors thank the sponsor for the financial grant that was necessary towards accomplishment of this work. We also appreciate the material and moral support from the management of The Nelson Mandela African Institution of Science and Technology (NM-AIST) and Mkwawa University College of Education (MUCE).

\section{References}

[1] Eregha, P.B. (2010) Interest Rate Variation and Investment Determination in Nigeria. International Business Management, 4, 257.

[2] Tchakarov, I. and Elekdag, S.A. (2006) The Role of Interest Rates in Business Cycle Fluctuations in Emerging Market Countries: The Case of Thailand. IMF Working Paper. https://doi.org/10.5089/9781451863703.001

[3] Cagan, P. (1969) The Influence of Interest Rates on the Duration of Business Cycles. $\mathrm{N}$ BER Essays on Interest Rates, 1, 3-28.

[4] Sharpe, S.A. and Suarez, G. (2013) The Insensitivity of Investment to Interest Rates: Evidence from a Survey of CFOs. FEDS Working Paper.

[5] Karim, Z.A. and Azman-Saini, W.N.W. (2013) Firm-Level Investment and Monetary Policy in Malaysia: Do the Interest Rate and Broad Credit Channels Matter? Journal of the Asia Pacific Economy, 18, 396-412. https://doi.org/10.1080/13547860.2012.742686

[6] Jorgenson, D.W. (1963) Capital Theory and Investment Behavior. The American Economic Review, 53, 247-259.

[7] Calderón, C. and Fuentes, R. (2010) Characterizing the Business Cycles of Emerging 
Economies. World Bank Policy Research Working Paper Series, 5343. https://doi.org/10.1596/1813-9450-5343

[8] Chetty, R. (2007) Interest Rates, Irreversibility, and Backward-Bending Investment. The Review of Economic Studies, 74, 67-91. https://doi.org/10.1111/j.1467-937x.2007.00414.x

[9] Blankenau, W., Kose, M.A. and Yi, K. (2001) Can World Real Interest Rates Explain Business Cycles in a Small Open Economy? Journal of Economic Dynamics and Control, 25, 867-889.

[10] Neumeyer, P.A. and Perri, F. (2005) Business Cycles in Emerging Economies: The Role of Interest Rates. Journal of monetary Economics, 52, 345-380.

[11] Décamps, J. and Villeneuve, S. (2007) Optimal Dividend Policy and Growth Option. Finance and Stochastics, 11, 3-27. https://doi.org/10.1007/s00780-006-0027-z

[12] Bo, H. and Sterken, E. (2002) Volatility of the Interest Rate, Debt and Firm Investment: Dutch Evidence. Journal of Corporate Finance, 8, 179-193.

[13] Chevalier, E., Vath, V.L. and Scotti, S. (2013) An Optimal Dividend and Investment Control Problem under Debt Constraints. SIAM Journal on Financial Mathematics, 4, 297-326. https://doi.org/10.1137/120866816

[14] Peng, L. and Thibodeau, T.G. (2011) Interest Rate and Investment under Uncertainty: Evidence from Commercial Real Estate Capital Expenditures. Working Paper.

[15] Bader, M. and Malawi, A.I. (2010) The Impact of Interest Rate on Investment in Jordan: A Cointegration Analysis. Economics and Administration, 24, 1.

[16] Wang, X. and Wang, Y. (2010) Optimal Investment and Consumption with Stochastic Dividends. Applied Stochastic Models in Business and Industry, 26, 792 808. https://doi.org/10.1002/asmb.823

[17] Han, X. and Yi, F. (2015) A Stochastic Control Model of Investment, Production, and Consumption on a Finite Horizon. Mathematical Methods in the Applied Sciences, 2, 255. https://doi.org/10.1002/mma.3129

[18] Hugonnier, J., Malamud, S. and Morellec, E. (2015) Capital Supply Uncertainty, Cash Holdings, and Investment. Review of Financial Studies, 28, 391-445. https://doi.org/10.1093/rfs/hhu081

[19] Gibson, R., Lhabitant, F. and Talay, D. (2010) Modeling the Term Structure of Interest Rates: A Review of the Literature. Foundations and Trends in Finance, 5, 1-2. https://doi.org/10.1561/0500000032

[20] Huang, T.T., Sun, B.Q. and Chen, X. (2014) Re-Specification of Affine Term Structure Models: The Linkage to Empirical Investigations. Applied Mathematical Finance, 21, 523-554. https://doi.org/10.1080/1350486X.2014.896510

[21] Akyildirim, E., Güney, I.E., Rochet, J. and Soner, H.M. (2014) Optimal Dividend Policy with Random Interest rates. Journal of Mathematical Economics, 51, 93-101.

[22] Løkka, A. and Zervos, M. (2008) Optimal Dividend and Issuance of Equity Policies in the Presence of Proportional Costs. Insurance: Mathematics and Economics, 42, 954-961.

[23] Pierre, E., Villeneuve, S. and Warin, X. (2014) Capital Investment and Liquidity Management with Collateralized Debt. TSE Working Paper, 38, 1070-1080. 
Submit or recommend next manuscript to SCIRP and we will provide best service for you:

Accepting pre-submission inquiries through Email, Facebook, LinkedIn, Twitter, etc. A wide selection of journals (inclusive of 9 subjects, more than 200 journals)

Providing 24-hour high-quality service

User-friendly online submission system

Fair and swift peer-review system

Efficient typesetting and proofreading procedure

Display of the result of downloads and visits, as well as the number of cited articles Maximum dissemination of your research work

Submit your manuscript at: http://papersubmission.scirp.org/

Or contact jmf@scirp.org 